\title{
Not a New Story: Place- and Race-Based Disparities in COVID-19 and Influenza Hospitalizations among Medicaid-Insured Adults in New York City
}

\author{
Renata E. Howland · Scarlett Wang • \\ Ingrid Gould Ellen $\cdot$ Sherry Glied
}

Accepted: 7 January 2022 / Published online: 22 February 2022

(C) The New York Academy of Medicine 2022, corrected publication 2022

\begin{abstract}
While SARS-CoV-2 is a novel virus, contagious respiratory illnesses are not a new problem. Limited research has examined the extent to which place- and race-based disparities in severe illness are similar across waves of the COVID-19 pandemic and historic influenza seasons. In this study, we focused on these disparities within a low-income population, those enrolled in Medicaid in New York City. We used 2015-2020 New York State Medicaid claims to compare the characteristics of patients hospitalized with COVID-19 during three separate waves of 2020 (first wave: January 1-April 30, 2020; second wave: May 1-August 31, 2020; third wave: September 1-December 31, 2020) and with influenza during the 2016 (July 1, 2016-June 30, 2017) and 2017 influenza seasons (July 1, 2017-June 30, 2018). We found that patterns of hospitalization by race/ethnicity and ZIP code across the two influenza seasons and the first wave of COVID-19 were similar (increased risk among non-Hispanic Black $(\mathrm{aOR}=1.17,95 \%$ CI: 1.10-1.25) compared with non-Hispanic white Medicaid recipients). Black/white disparities in hospitalization dissipated in the second COVID wave
\end{abstract}

R. E. Howland $(\bowtie) \cdot S$. Wang $\cdot$ I. G. Ellen $\cdot$ S. Glied Wagner Graduate School of Public Service, New York University, New York, NY 10012, USA

e-mail: Renata.howland@nyu.edu

I. G. Ellen

Furman Center for Real Estate and Urban Policy, New

York University, New York, NY 10012, USA and reversed in the third wave. The commonality of disparities across influenza seasons and the first wave of COVID-19 suggests there are community factors that increase hospitalization risk across novel respiratory illness incidents that emerge in the period before aggressive public health intervention. By contrast, convergence in hospitalization patterns in later pandemic waves may reflect, in part, the distinctive public health response to COVID-19.

Keywords Hospitalization - SARS-CoV-2 . Influenza $\cdot$ Healthcare disparities

\section{Introduction}

In the early days of the COVID-19 pandemic, some thought that the novel strain of coronavirus (SARSCoV-2) would act as a "great equalizer," affecting individuals equally because no one in the population was immune or protected by a vaccine [1]. Yet, surveillance reports have consistently documented significant differences in infection, severe illness, and mortality by age, sex, race/ethnicity, socioeconomic status, and baseline health status [2-4]. The disproportionate effect of COVID-19 on people of color has been particularly alarming [5]. Black, Hispanic, and American Indian or Alaska Native populations have had between 2 and 4 times the rates of hospitalization and death compared with white non-Hispanics [6]. 
Unfortunately, disparities in viral respiratory infection are not a new phenomenon [7] - they are only new as a focus of attention. Historically, high rates of hospitalization have been reported during seasonal influenza seasons among Black, American Indian, and Hispanic or Latino populations [8]. Blumenshine et al. (2008) suggest three pathways through which underlying differences in a social position related to income and race manifest in influenza disparities-[1] disparities in exposure to infection, [2] disparities in susceptibility to severe disease due to a higher prevalence of underlying conditions, and [3] differential access to healthcare and treatment, once people become ill [9]. During the $\mathrm{H} 1 \mathrm{~N} 1$ pandemic, for example, disparities at all three stages synergistically interacted to increase morbidity and mortality among Hispanic and Black populations [10].

Despite the apparent similarities between the clinical characteristics and transmission routes of influenza and SARS-CoV-2, limited research to date has directly examined to what extent place- and racebased disparities in COVID-19 hospitalizations are similar to those in seasonal influenza. Few studies have also considered how disparities may have changed over the course of the COVID-19 pandemic, as infection rates declined, lockdown measures were implemented, and treatments became available, changing the dynamics of exposure, susceptibility, and access. Moreover, because most studies examine population-level data, prior estimates of the extent of place- and race-based disparities may have been confounded by differences in income across groups.

To address these gaps, we use a cohort of Medicaid-insured adults in New York City (NYC) to compare disparities in COVID-19 hospitalizations over three distinct waves of the pandemic to prior influenza seasons. Given the income eligibility requirements of the Medicaid program, our sample is relatively homogenous economically allowing us to examine disparities with limited confounding due to differences in socioeconomic status. By examining disparities across viral agents, these findings will provide information about who is most at risk for severe respiratory infectious illness within a low-income population and whether these trends change in response to public health policies.

\section{Methods}

\section{Data Source}

We used 2016-2020 New York State Medicaid data, which includes both fee-for-service and encounter claims generated from managed care plans ( Historically, underreporting of encounters was a concern; however, NYS encounter claims have a similar level of completeness as traditional fee-for-service claims). We created three cohorts of Medicaid recipients who were enrolled during the COVID-19 pandemic but before the widespread availability of vaccines (January-December 2020) or during the 2016 or 2017 influenza seasons (July-June) (Fig. 1). We selected these seasons because they capture both a moderate (2016) and severe (2017) flu season [1], and they occurred after the introduction of the ICD$10-\mathrm{CM}$, making comparisons over time more tractable. For each cohort, we selected adults 18 years or older who were living in NYC as of the first month of the season. Recipients had to be continuously enrolled $(10+$ months $)$ during the relevant season, as well as in the year prior to the season so that we could obtain baseline health status. Thus, our sample included approximately 1.9 million adults in the 2020 pandemic cohort, and 1.7 million adults during each of the 2016-2017 and 2017-2018 influenza seasons. The Institutional Review Board at New York University reviewed the study and provided an exemption as a secondary analysis of existing data.

Measures

We identified diagnoses of COVID-19 using the newly established ICD-10-CM code (U07.1), which was formally recommend for use as of March 18, 2020 [11]. That being said, our analysis is based on the date of admission (rather than the date of diagnosis). Therefore, we include 14 hospitalizations beginning in January and 42 hospitalizations beginning in February, who were discharged after March 18, 2020, and received a diagnosis of U07.1. Although these likely represent cases that contracted COVID-19 during their hospitalization, we left them in the sample to be consistent with the way we captured influenza in previous years. Comparison between hospitalizations with COVID-19 captured from Medicaid claims with those reported by the NYC Department of Health and Mental Hygiene 


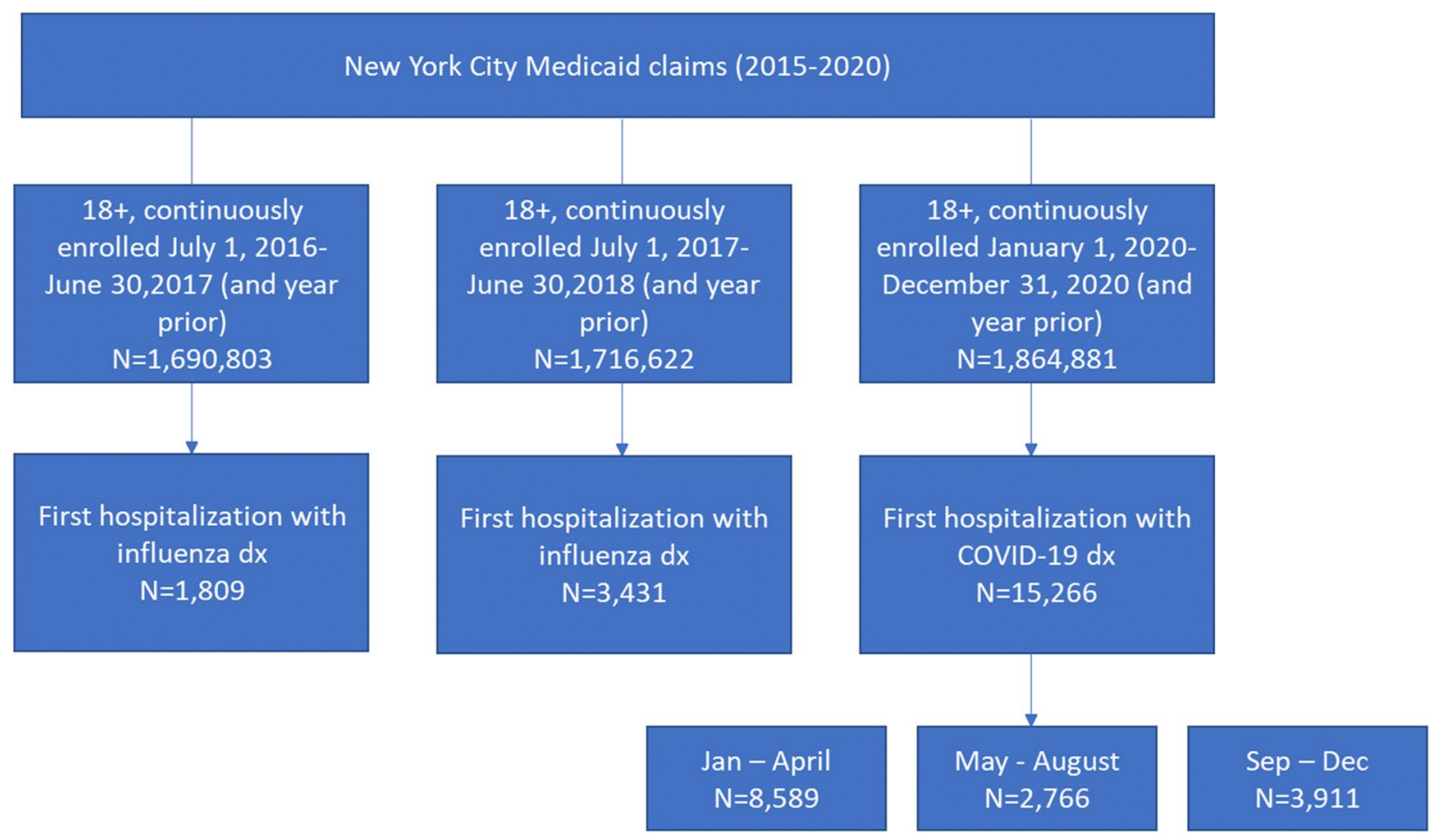

Fig. 1 Flowchart describing the study sample derived from New York City Medicaid claims, 2015-2020

show closely parallel trends (Appendix Fig. 3). A recent validation study found that U07.1 was utilized by US hospitals within 2 weeks of its release and the sensitivity, specificity, and positive predictive value on inpatient claims were very high (>90\%) compared with microbiology reports (13). Influenza was identified using the clinical classification code 123, which is a series of ICD-10-CM codes for different types of influenza viruses with and without other clinical symptoms, such as pneumonia [12]. If individuals had more than one hospitalization in a season, only the first event was included.

Patient demographic characteristics were extracted from Medicaid enrollment files, including age (categorized as 18-39, 40-49, 50-59, 60-69, 70-79, or $80+$ ), sex (categorized as female or male/other), race/ ethnicity (categorized as non-Hispanic white, Black, Asian and Pacific Islander, Native American and Alaska Native, Hispanic, and other), and dual Medicaid/Medicare eligibility. We identified the ZIP Code in which patients were living at the beginning of each season (July 1, 2016, July 1, 2017, or January 1, 2020) to generate maps (our past research shows that the address information in Medicaid is high quality, with updates conducted at least annually during reenrollment). Finally, we created flags for pre-existing conditions based on 1 year of historical claims. We selected conditions that have been identified as associated with COVID-19 mortality in other publications [13], including heart disease, asthma, diabetes, cancer, kidney and liver disease, dementia, and arthritis. Conditions were categorized based on the presence of diagnosis codes that fall into clinical classification groups, designed by the Healthcare Utilization and Cost Project to represent clinically meaningful conditions [12].

\section{Statistical Analysis}

We examined racial/ethnic disparities in hospitalization using logistic regression models (separate for each outcome). Adjusted models included age, sex, dual eligibility (Medicare/Medicaid), and all preexisting conditions. In order to examine how risk factors changed over the course of the pandemic, we stratified COVID-19 models by the date of hospital admission into three waves (first: January 1-April 30, 2020; second wave: May 1-August 31, 2020; 
and third wave: September 1-December 31, 2020). We present odds ratios and $95 \%$ confidence intervals. To examine differences by ZIP Code, we rank ordered the rate of hospitalization per the Medicaid adult population by ZIP Code within each season and wave and then estimated Spearman Correlation coefficients among ranks for the three waves of COVID and the two flu seasons. Data manipulation and statistical analysis were conducted in SAS 9.2 (Cary, North Carolina). Maps were designed in Tableau (Tableau Software, Inc., Seattle, WA).

\section{Sensitivity Analyses}

To account for potential misclassification of pneumonia-related hospitalization that were not influenza related, we restricted hospitalizations during the 2016 and 2017 seasons to the months of October through March (when influenza is the most prevalent). We also restricted COVID-19 hospitalizations to those with a primary diagnosis of COVID-19 to account for cases that were identified secondary to other reasons for hospitalization. Third, in order to account for potential differences in influenza versus COVID-19 coding, we re-ran the influenza models with influenza-like illness as the outcome, which is a broader definition of influenza including common symptoms but not a laboratory-confirmed diagnosis. Fourth, to control for differences in the criteria for hospital admission over time, we re-ran models using only those hospitalizations with procedure codes for ventilation (an indicator for severity). Finally, we re-ran our analysis using an imputation method for race and ethnicity, which was missing from $18 \%$ of the sample. We used the R package "wru" to implement the imputation, which includes surname, census tract, age, and sex. We then re-ran regression models to assess for any meaningful differences in trends.

\section{Results}

From January to December 2020, there were 15,261 inpatient hospitalizations with a diagnosis of COVID19 among adults on Medicaid in NYC (Table 1). This number is between 4 and 8 times greater than the number of influenza hospitalizations during $2016(n=1803)$ and $2017(n=3424)$ influenza seasons, respectively. More than half of all COVID-19 hospitalizations $(n=8583)$ took place in the first wave of the pandemic (through the end of April 2020). Approximately 18\% $(n=2768)$ of all COVID-19 hospitalizations took place from May to August and 26\% $(n=3910)$ occurred from September to December.

Across COVID and both influenza seasons, we found a similar proportion of hospitalizations by race/ethnicity across seasons (Table 1). For example, individuals that were non-Hispanic Black made up $19.6 \%$ of all COVID-19 hospitalizations, $17.0 \%$ of influenza hospitalizations in 2016, and $19.2 \%$ of influenza hospitalizations in 2017 (this is roughly similar to the Black proportion of Medicaid recipients by year (19-20\%, data not shown)). The only exception to this pattern was Hispanics, who made up $26 \%$ of COVID-19 hospitalizations but roughly 35\% of influenza hospitalizations; however, there was also a parallel increase in the proportion of hospitalizations recorded as unknown race/ethnicity over time, which could account for this difference. Across waves of the COVID-19 pandemic, the proportion of hospitalizations to white non-Hispanics and Asian and Pacific Islanders increased (from 18 in the first wave to $22 \%$ in the third wave and from 8 to $14 \%$ respectively), whereas the proportion to non-Hispanic Blacks decreased (from 25 to $16 \%$ ). The proportion of hospitalizations to Hispanics stayed the same. Appendix Table 3 presents the raw disparities by race/ethnicity as odds ratios

In adjusted regression models, differences in risk by race/ethnicity were less pronounced during COVID-19 compared to previous influenza seasons, when Black and Hispanic Medicaid recipients had a higher risk compared to non-Hispanic whites (Table 2). For example, where Black and Hispanics had between $24-25 \%$ and $21-61 \%$ increased risk of hospitalization compared to non-Hispanic whites during the 2016 and 2017 influenza seasons, there was no difference during COVID-19. Only Asian and Pacific Islanders had a consistently lower risk of hospitalization across all three seasons.

When COVID-19 hospitalizations are stratified across waves of the pandemic, the racial/ethnic patterns change dramatically over time (Table 2). Disparities between non-Hispanic Blacks and whites were strong in the first wave of the pandemic, closely mirroring influenza patterns, but declined over the course of 2020. Compared to non-Hispanic whites, non-Hispanic Blacks were $17 \%$ more likely to be 
hospitalized during the early wave of the pandemic $(\mathrm{aOR}=1.17,95 \%$ CI: $1.10-1.25)$, and $25 \%$ and $23 \%$ were more likely to be hospitalized in the 2016 and 2017 flu season, respectively $(\mathrm{aOR}=1.25,95 \% \mathrm{CI}$ : $1.07-1.46$ and $\mathrm{aOR}=1.24$, 95\% CI:1.11-1.37). By the fall of 2020, the risk of hospitalization for nonHispanic Blacks was significantly lower than the risk for non-Hispanic whites $(0.67,95 \%$ CI: 0.60-0.74).
Hispanic adults also had an increased risk of hospitalization compared to non-Hispanic whites during the early wave of the pandemic $(\mathrm{OR}=1.20,95 \%$ : 1.13-1.28) (Appendix Table 3), but this was attenuated in adjusted models and was not present in later waves of the pandemic.

ZIP-level maps show similarities across years in the geography of hospitalization for adults enrolled in
Table 1 Demographic and clinical characteristics of Medicaid recipients hospitalized with seasonal influenza (July 1, 2016, to June 30,2017 , and July 1, 2017, to June 30, 2017) or dur- ing the first, second, or third wave of the COVID-19 pandemic COVID-19 (January 1 to December 2020), New York City

\begin{tabular}{|c|c|c|c|c|c|c|}
\hline No. $(\%)$ & 2016 influenza & 2017 influenza & 2020 COVID & First wave & Second wave & Third wave \\
\hline Total & 1803 & 3424 & 15261 & 8583 & 2768 & 3910 \\
\hline \multicolumn{7}{|l|}{ Race/ethnicity } \\
\hline White Non-Hispanic & 306 (17) & 662 (19) & $2993(20)$ & 1564 (18) & 557 (20) & $872(22)$ \\
\hline Black Non-Hispanic & $383(21)$ & $867(25)$ & $3385(22)$ & $2126(25)$ & $625(23)$ & $634(16)$ \\
\hline Asian and Pacific Islander & $192(11)$ & $300(9)$ & $1421(9)$ & $674(8)$ & $215(8)$ & $532(14)$ \\
\hline Other Non-Hispanic races & $122(7)$ & $226(7)$ & $1191(8)$ & $675(8)$ & $215(8)$ & $301(8)$ \\
\hline Hispanic & $698(39)$ & $1187(35)$ & $4028(26)$ & $2279(27)$ & $695(25)$ & $1054(27)$ \\
\hline Unknown & $102(6)$ & $189(6)$ & $2243(15)$ & $1265(15)$ & $461(17)$ & $517(13)$ \\
\hline \multicolumn{7}{|l|}{ Age groups } \\
\hline $18-39$ & $273(15)$ & $408(12)$ & $2846(19)$ & $1311(15)$ & $847(31)$ & $688(18)$ \\
\hline $40-49$ & $135(8)$ & $289(8)$ & $1648(11)$ & $996(12)$ & $283(10)$ & $369(9)$ \\
\hline $50-59$ & 297 (17) & $662(19)$ & $3006(20)$ & $1851(22)$ & 457 (17) & $698(18)$ \\
\hline $60-69$ & 335 (19) & 657 (19) & $3253(21)$ & $2017(24)$ & $449(16)$ & $787(20)$ \\
\hline $70-79$ & $318(18)$ & $609(18)$ & $2,385(16)$ & $1348(16)$ & $361(13)$ & $676(17)$ \\
\hline $80+$ & $445(25)$ & $799(23)$ & $2123(14)$ & $1060(12)$ & $371(13)$ & $692(18)$ \\
\hline \multicolumn{7}{|l|}{ Sex } \\
\hline Male & $663(37)$ & $1318(38)$ & 7447 (49) & $4473(52)$ & $1168(42)$ & $1836(47)$ \\
\hline Female & $1140(63)$ & $2113(62)$ & $7784(51)$ & $4110(48)$ & $1600(58)$ & $2074(53)$ \\
\hline \multicolumn{7}{|l|}{ Pre-existing conditions } \\
\hline Heart disease & $620(34)$ & $1231(36)$ & $4308(28)$ & $2466(29)$ & 757 (27) & $1085(28)$ \\
\hline Asthma & $530(39)$ & $1011(30)$ & $2458(16)$ & $1345(16)$ & $465(17)$ & $648(17)$ \\
\hline Diabetes & $829(46)$ & $1726(50)$ & $7361(48)$ & $4338(51)$ & $1173(42)$ & $1850(47)$ \\
\hline Cancer & $238(13)$ & 397 (12) & $1496(10)$ & $798(9)$ & $259(9)$ & $439(11)$ \\
\hline Kidney disease & $367(20)$ & $697(20)$ & 2947 (19) & $1833(21)$ & $476(17)$ & $638(16)$ \\
\hline Liver disease & $212(12)$ & $422(12)$ & $2308(15)$ & $1363(16)$ & $420(15)$ & $525(13)$ \\
\hline Dementia & $245(14)$ & $424(12)$ & $1787(12)$ & $1072(12)$ & $340(12)$ & $375(10)$ \\
\hline Rheumatoid arthritis & $69(4)$ & $100(3)$ & $374(3)$ & $199(2)$ & $78(3)$ & $97(2)$ \\
\hline$\geq 1$ condition & $1422(79)$ & $2674(78)$ & $10790(71)$ & $6235(73)$ & $1823(66)$ & $2732(70)$ \\
\hline \multicolumn{7}{|l|}{ Dual Medicare/Medicaid } \\
\hline No & $818(45)$ & $1571(46)$ & $9083(60)$ & $5126(60)$ & $1732(63)$ & $2225(57)$ \\
\hline Yes & $985(55)$ & $1853(53)$ & $6178(41)$ & $3457(40)$ & $1036(37)$ & $1685(43)$ \\
\hline
\end{tabular}

The 2016 influenza season is from July 1, 2016, to June 30, 2017; the 2017 influenza seasons is from July 1, 2017, to June 30, 2018; the COVID-19 season is from January 1, 2020, to December 31, 2021; pre-existing conditions were coded based on the presence of clinical classification codes, which group ICD-10-CM diagnosis codes into clinically meaningful categories [HCUP]. Note column percentages may not add up to 100 due to rounding (source: New York State Medicaid Claims, 2015-2020) 
Table 2 Adjusted odds ratio between patient characteristics and influenza hospitalization or COVID-19 hospitalization during the first, second or third wave of the pandemic among adults continuously enrolled in Medicaid in New York City, 2015-2020

\begin{tabular}{|c|c|c|c|c|c|c|}
\hline & $\begin{array}{l}2016 \text { influenza } \\
\text { Adjusted OR } \\
(95 \% \mathrm{CI})\end{array}$ & $\begin{array}{l}2017 \text { influenza } \\
\text { Adjusted OR } \\
(95 \% \mathrm{CI})\end{array}$ & $\begin{array}{l}\text { COVID-19 } \\
\text { Adjusted OR } \\
(95 \% \mathrm{CI})\end{array}$ & $\begin{array}{l}\text { First wave } \\
\text { Adjusted OR } \\
(95 \% \mathrm{CI})\end{array}$ & $\begin{array}{l}\text { Second wave } \\
\text { Adjusted OR } \\
(95 \% \mathrm{CI})\end{array}$ & $\begin{array}{l}\text { Third wave } \\
\text { Adjusted OR } \\
(95 \% \mathrm{CI})\end{array}$ \\
\hline \multicolumn{7}{|l|}{ Race/ethnicity } \\
\hline $\begin{array}{l}\text { White Non- } \\
\text { Hispanici }\end{array}$ & REF & REF & REF & REF & REF & REF \\
\hline $\begin{array}{l}\text { Black Non-His- } \\
\text { panic }\end{array}$ & $1.25(1.07-1.46)$ & 1.24 (1.11-1.37) & $0.99(0.94-1.04)$ & $1.17(1.10-1.25)$ & $0.97(0.87-1.09)$ & $0.67(0.60-0.74)$ \\
\hline $\begin{array}{l}\text { Asian and Pacific } \\
\text { Islander }\end{array}$ & $0.77(0.65-0.93)$ & $0.52(0.45-0.60)$ & $0.43(0.40-0.46)$ & $0.38(0.35-0.42)$ & $0.38(0.32-0.45)$ & $0.56(0.51-0.63)$ \\
\hline $\begin{array}{l}\text { Other Non-His- } \\
\text { panic races }\end{array}$ & $1.06(0.86-1.31)$ & $0.89(0.77-1.04)$ & $0.92(0.86-0.98)$ & $0.98(0.89-1.07)$ & $0.91(0.78-1.06)$ & $0.82(0.72-0.93)$ \\
\hline Hispanic & $1.61(1.40-1.84)$ & $1.21(1.10-1.34)$ & $0.98(0.93-1.03)$ & $1.05(0.98-1.12)$ & $0.95(0.85-1.06)$ & $0.88(0.80-0.97)$ \\
\hline Unknown & $0.78(0.62-0.99)$ & $0.62(0.52-0.73)$ & $0.91(0.86-0.97)$ & $1.01(0.93-1.09)$ & $0.88(0.77-1.00)$ & $0.77(0.68-0.86)$ \\
\hline \multicolumn{7}{|l|}{ Age group } \\
\hline $18-39$ & REF & REF & REF & REF & REF & REF \\
\hline $40-49$ & $1.04(0.84-1.28)$ & $1.49(1.28-1.73)$ & $1.38(1.30-1.47)$ & $1.80(1.66-1.96)$ & $0.78(0.68-0.90)$ & $1.31(1.15-1.48)$ \\
\hline $50-59$ & $1.55(1.30-1.84)$ & $2.24(1.97-2.55)$ & $1.82(1.72-1.91)$ & $2.38(2.21-2.56)$ & $0.89(0.79-1.00)$ & $1.84(1.65-2.06)$ \\
\hline $60-69$ & $1.69(1.40-2.03)$ & $2.15(1.87-2.47)$ & $1.97(1.85-2.08)$ & $2.61(2.42-2.83)$ & $0.80(0.69-0.91)$ & $2.17(1.93-2.43)$ \\
\hline $70-79$ & $2.12(1.72-2.62)$ & $2.67(2.29-3.31)$ & $2.17(2.01-2.33)$ & $2.64(2.39-2.91)$ & $0.84(0.71-1.00)$ & $2.99(2.60-3.45)$ \\
\hline $80+$ & $3.63(2.94-4.47)$ & $4.40(3.75-5.15)$ & $2.43(2.25-2.63)$ & $2.57(2.31-2.86)$ & $0.99(0.83-1.19)$ & $4.21(3.63-4.88)$ \\
\hline \multicolumn{7}{|l|}{ Sex } \\
\hline Male & REF & REF & REF & REF & REF & REF \\
\hline Female & $1.02(0.93-1.13)$ & $0.99(0.92-1.06)$ & $0.75(0.72-0.77)$ & $0.67(0.64-0.70)$ & $0.99(0.92-1.07)$ & $0.79(0.74-0.84)$ \\
\hline \multicolumn{7}{|l|}{$\begin{array}{r}\text { Pre-existing } \\
\text { conditions }\end{array}$} \\
\hline Heart disease & $1.86(1.66-2.09)$ & $2.00(1.84-2.17)$ & $1.77(1.70-1.84)$ & $1.68(1.59-1.78)$ & $2.08(1.88-2.30)$ & $1.71(1.58-1.85)$ \\
\hline Asthma & $2.81(2.53-3.13)$ & $2.88(2.66-3.11)$ & $1.32(1.26-1.38)$ & $1.24(1.17-1.32)$ & $1.34(1.20-1.48)$ & $1.47(1.35-1.60)$ \\
\hline Diabetes & $1.14(1.02-1.26)$ & $1.34(1.24-1.44)$ & $1.66(1.60-1.72)$ & $1.73(1.65-1.82)$ & $1.51(1.38-1.65)$ & $1.59(1.48-1.70)$ \\
\hline Cancer & $1.48(1.29-1.71)$ & $1.24(1.12-1.38)$ & $1.12(1.06-1.18)$ & $1.03(0.96-1.11)$ & $1.14(1.0-1.30)$ & $1.29(1.16-1.43)$ \\
\hline Kidney disease & $2.39(2.10-2.72)$ & $2.17(1.98-2.38)$ & $2.36(2.26-2.47)$ & $2.58(2.43-2.73)$ & $2.26(2.02-2.53)$ & $1.84(1.67-2.02)$ \\
\hline Liver disease & $1.38(1.19-1.60)$ & $1.37(1.23-1.52)$ & $1.54(1.47-1.62)$ & $1.57(1.48-1.67)$ & $1.68(1.50-1.87)$ & 1.35 (1.23-1.49) \\
\hline Dementia & $1.41(1.21-1.64)$ & $1.30(1.16-1.45)$ & $1.98(1.87-2.10)$ & $2.21(2.06-2.38)$ & $2.32(2.04-2.65)$ & $1.31(1.16-1.47)$ \\
\hline $\begin{array}{l}\text { Rheumatoid } \\
\text { arthritis }\end{array}$ & $1.20(0.94-1.54)$ & $1.03(0.84-1.26)$ & $1.10(0.99-1.23)$ & $1.04(0.90-1.20)$ & $1.33(1.06-1.67)$ & $1.10(0.90-1.35)$ \\
\hline \multicolumn{7}{|l|}{$\begin{array}{l}\text { Dual Medicare/ } \\
\text { Medicaid }\end{array}$} \\
\hline No & REF & REF & REF & REF & REF & $\mathrm{REF}$ \\
\hline Yes & $1.38(1.21-1.58)$ & $1.35(1.23-1.49)$ & $0.87(0.83-0.92)$ & $0.86(0.81-0.92)$ & $1.07(0.95-1.21)$ & $0.80(0.72-0.88)$ \\
\hline
\end{tabular}

The 2016 influenza season is from July 1, 2016, to June 30, 2017; the 2017 influenza seasons is from July 1, 2017, to June 30, 2018; the COVID-19 season is from January 1, 2020, to December 31, 2021; all models are adjusted for age, race/ethnicity, sex, dual eligibility, and all pre-existing conditions and run using logistic regression. AOR, adjusted odds ratio; $C I$, confidence interval (source: New York State Medicaid Claims, 2015-2020)

Medicaid (Fig. 2). The spatial distribution of COVID19 hospitalizations was more similar to the 2017 influenza season $(r h o=0.41)$ than the 2016 influenza season $($ rho $=0.34)$ (data not shown). Notably, the
ZIP distributions of hospitalizations for influenza in both seasons were actually closer to that for COVID19 than they were to each other $(r h o=0.31)$. Similar to the patterns with racial disparities, the distribution 
Hospitalization Rates per $100 \mathrm{~K}$ by Quartiles of ZCTA

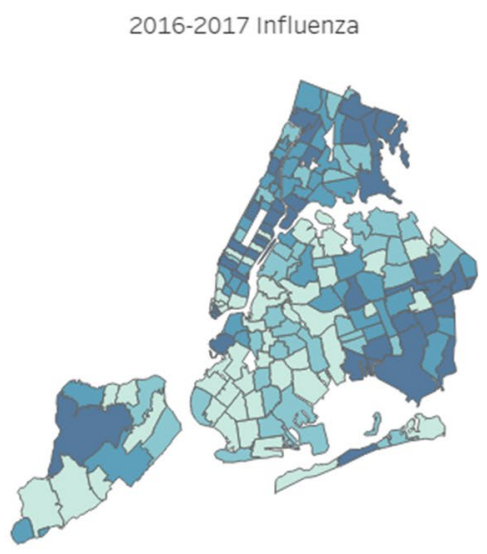

2020 COVID (January - April)

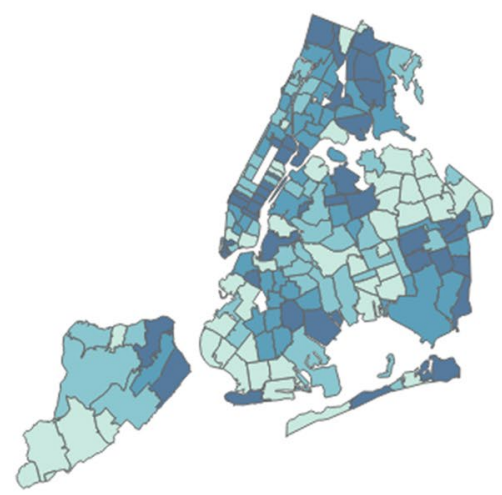

2017-2018 Influenza

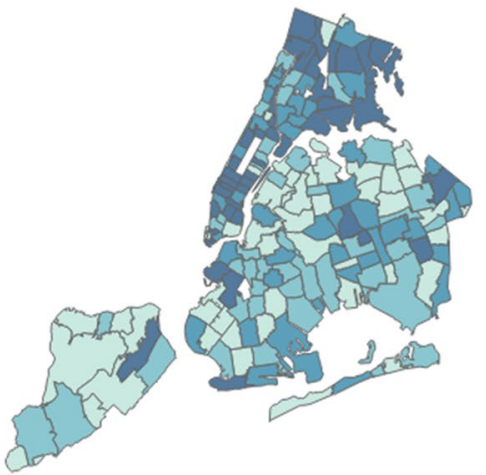

2020 COVID (May - August)

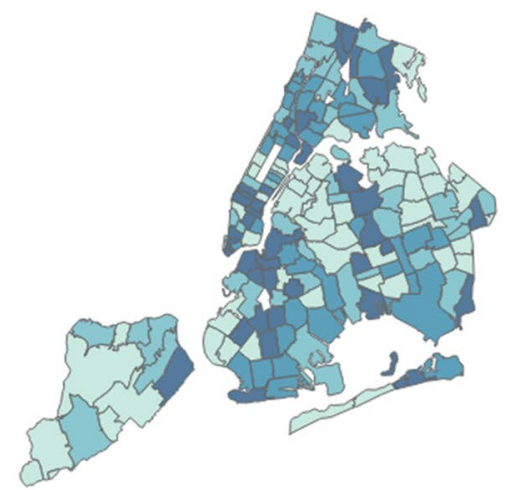

2020 COVID (whole year)

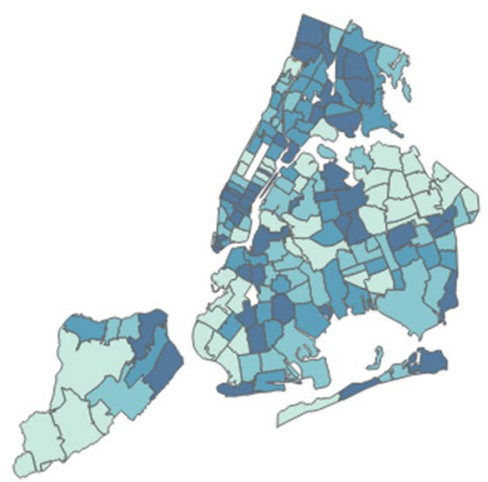

2020 COVID (September - December)

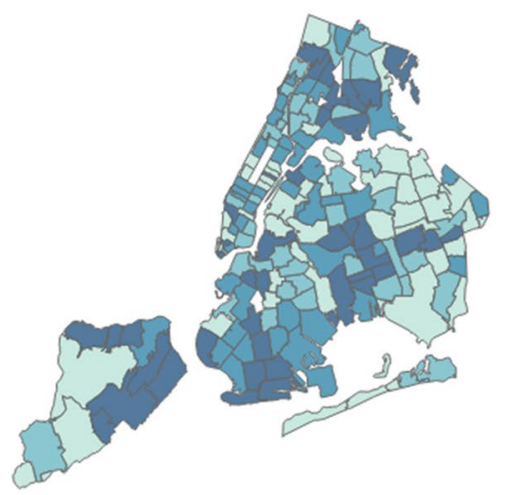

Fig. 2 Hospitalization rates per 100,000 Medicaid recipients by quartiles of ZIP Code tabulation area (ZCTA) during the 2016 and 2017 influenza seasons and COVID-19

of COVID-19 hospitalizations looked the most like influenza seasons in the early wave of COVID (rho $=0.35$ and 0.37 for 2016 and 2017 , respectively) and declined over time to rho $=0.03$ and 0.22 in the third wave.

When we restricted influenza hospitalizations to October through March (to reduce misclassification of pneumonia-related hospitalizations), we found that the majority of influenza hospitalizations occurred during this narrower time frame $(87.1 \%$ and $94.4 \%$ in 2016 and 2017, respectively) and running the regression with this subset of hospitalizations did not change the findings materially (Appendix Table 4). To account for diagnoses of COVID-19 that might be secondary to other reasons for hospitalizations, we restricted to hospitalizations where COVID-19 was the primary diagnosis. We found that approximately
58\% ( $n=8865)$ hospitalizations had COVID-19 as the primary diagnosis at discharge. When we looked at regression models among this subset, the findings were largely unchanged with the exception of age, which showed a stronger effect at older ages than in the main results (Appendix Table 5. Findings were also unchanged when we broadened the definition of influenza to influenza-like illness (ILI) for both the 2016 and 2017 season (Appendix Table 6). When we looked at only those hospitalizations with ventilation, we noted treatment patterns did change over time (ranging from 6 to $10 \%$ across influenza and COVID19 seasons), but these patterns did not affect the overall results (data not shown). Finally, our imputation method predicted that the majority of individuals with unknown race/ethnicity were Hispanic. When we used the predicted values for individuals with 
unknown race/ethnicity, the values among Hispanics were slightly attenuated (consistent with the fact that the unknown had a low risk of hospitalization), but still statistically significant and trends overall did not change substantially (data not shown).

\section{Discussion}

Our findings suggest that place- and race-disparities in hospitalization rates for respiratory infectious disease are not new or different. Patterns of hospitalizations by race/ethnicity across two historic influenza seasons and the first wave of the COVID-19 pandemic were similar, but changed over the second and third waves of the pandemic. This suggests that pre-existing structural factors, common to COVID and influenza, may have played a role in generating disparities in the risk of exposure and severe illness from the very start of the pandemic. Differences in infection rates in the first wave may have contributed to a reduction in the size of the susceptible population and, as a result, a decline in disparities. It is also possible that public health policy changes may have been instrumental in mitigating disparities over time.

While many studies have documented the racial/ ethnic disparities in COVID-19 hospitalizations [14], only a handful have directly compared COVID-19 with historical influenza patterns. These studies have largely focused on the clinical complications and outcomes among those hospitalized [15-17], though some include patient characteristics as part of their descriptive analysis [18-20] or as part of a focused analysis among one ethnic group [21]. Direct comparison between these studies and ours is difficult because most are limited to data early in the pandemic, include different baseline influenza years, and utilize populations with different socioeconomic variation than ours. For example, two studies (from the Veterans Health Administration and Cook County, Illinois) reported even greater racial/ethnic disparities during COVID-19, with higher rates of COVID-19 hospitalizations among Black and Hispanic populations compared with previous influenza seasons [19, 21]. This difference may be related to the fact that our sample is relatively homogenous economically compared to other samples.

In addition to our focus on a low-income population, our study is also one of the first to examine how the characteristics of patients hospitalized with COVID-19 changed over the course of 2020, which is important to consider in light of changes in underlying infection rates, knowledge about transmission, social distancing policies, and treatment options that became available over time. Our findings suggest that place- and race-based disparities in COVID-19 were present early in the pandemic and were consistent with trends present in previous influenza seasons. The declining relative risk of hospitalizations among Black and Hispanic patients over waves of the pandemic in particular is supported by a recent analysis from the CDC COVID-19 Response team [22], which found that racial/ethnic disparities were largest in the early pandemic and decreased over time. Immunity acquired through earlier infection may explain part of this difference. The increased risk early in the pandemic suggests that underlying structural factors, such as crowded housing, neighborhood conditions, and employment patterns, rather than factors directly related to pandemic response (such as employment in essential jobs) played the most important role in generating disparities.

There are several limitations to consider. First, health care claims are not as accurate as the clinical measurement of viral infection and historic codes for influenza may be coded with less accuracy than COVID-19, which appears to have high sensitivity and specificity [23]. These differences in the quality of coding over time, or in the threshold for which people were hospitalized, could introduce bias in our comparisons. Second, our analysis of racial/ethnic disparities is limited by an increasing proportion of individuals with unknown race/ethnicity; however, our findings did not change using an imputation method. Third, we only had access to data through December 2020; therefore, we were unable to look at ongoing waves of COVID-19 . Finally, we restricted our population of interest to those continuously enrolled in Medicaid; therefore, our analysis may not be representative of the full burden of hospitalizations among the Medicaid population, such as people who enrolled only at the time of hospitalization. Our results also may not be generalizable to every influenza season; we selected one moderate and one severe season, both of which were dominated by influenza A (H3N2) [24, 25]; however, different strains develop every year and may affect slightly different populations. 


\section{Public Health Implications}

Despite historic trends in influenza and calls to address inequities in pandemic preparedness planning, many were surprised by disparities in infection, severe illness, and mortality during the COVID-19 pandemic. The commonality of disparities we found across both influenza seasons and the first wave of the COVID-19 pandemic suggests that there are pre-existing community factors that increase the risk of respiratory illness. Policymakers should use this opportunity and the national attention on disparities to re-examine policies that drive differences in exposure, severity, and mortality related to viral infections more generally. In particular, future research should examine the role of housing, community conditions, and participation in social programs to explain the variation and how these factors may have played a role in the early wave of the pandemic.

\section{Appendix}

Table 3 Crude odds ratio between patient characteristics and COVID-19 hospitalizations in the first, second, and third waves of the pandemic among adults continuously enrolled in Medicaid in New York City, 2020

\begin{tabular}{|c|c|c|c|c|c|c|}
\hline & 2016 influenza & 2017 influenza & COVID-19 & First wave & Second wave & Third wave \\
\hline & $\begin{array}{l}\text { Crude OR }(95 \% \\
\text { CI) }\end{array}$ & $\begin{array}{l}\text { Crude OR ( } 95 \% \\
\text { CI) }\end{array}$ & $\begin{array}{l}\text { Crude OR ( } 95 \% \\
\text { CI) }\end{array}$ & $\begin{array}{l}\text { Crude OR }(95 \% \\
\text { CI) }\end{array}$ & $\begin{array}{l}\text { Crude OR ( } 95 \% \\
\text { CI) }\end{array}$ & $\begin{array}{l}\text { Crude OR }(95 \% \\
\text { CI) }\end{array}$ \\
\hline \multicolumn{7}{|l|}{ Race/ethnicity } \\
\hline $\begin{array}{c}\text { White Non- } \\
\text { Hispanic }\end{array}$ & REF & REF & REF & REF & REF & REF \\
\hline $\begin{array}{l}\text { Black Non-His- } \\
\text { panic }\end{array}$ & $1.03(0.89-1.20)$ & $1.08(0.97-1.19)$ & $0.92(0.88-0.97)$ & $1.11(1.04-1.19)$ & $0.92(0.82-1.03)$ & $0.59(0.53-0.66)$ \\
\hline $\begin{array}{l}\text { Asian and Pacific } \\
\text { Islander }\end{array}$ & $0.58(0.49-0.70)$ & $0.42(0.37-0.48)$ & $0.43(0.41-0.46)$ & $0.40(0.36-0.43)$ & $0.36(0.31-0.42)$ & $0.56(0.50-0.62)$ \\
\hline $\begin{array}{l}\text { Other Non-His- } \\
\text { panic races }\end{array}$ & $0.89(0.72-1.10)$ & $0.76(0.66-0.89)$ & $0.88(0.82-0.94)$ & $0.95(0.87-1.04)$ & $0.85(0.73-1.00)$ & $0.76(0.67-0.87)$ \\
\hline Hispanic & $1.68(1.47-1.92)$ & $1.35(1.23-1.49)$ & $1.11(1.06-1.16)$ & $1.20(1.13-1.28)$ & $1.03(0.92-1.15)$ & $0.99(0.91-1.08)$ \\
\hline Unknown & $0.33(0.27-0.42)$ & $0.26(0.22-0.31)$ & $0.57(0.54-0.60)$ & $0.61(0.57-0.66)$ & $0.63(0.55-0.71)$ & $0.45(0.40-0.50)$ \\
\hline
\end{tabular}

The 2016 influenza season is from July 1, 2016, to June 30, 2017; the 2017 influenza seasons is from July 1, 2017, to June 30, 2018; the COVID-19 season is from January 1, 2020, to December 31, 2021; OR, odds ratio; CI, confidence interval (source: New York State Medicaid Claims, 2015-2020)

Figure 3 Comparison between COVID-19 hospitalizations reported by the NYC Department of Health and Mental Hygiene and in the Medicaid data as of March 2021

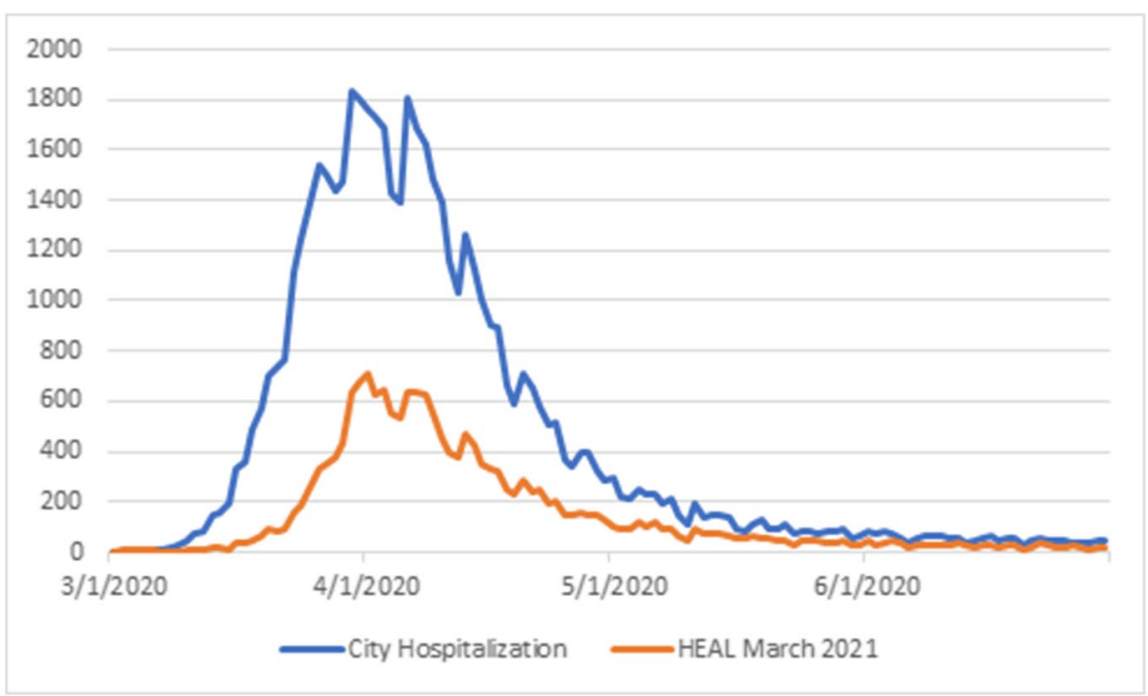


Table 4 Comparing trends during a concentrated flu season (October to March) with the full year in 2016 and 2017 in order to rule out the effect of non-influenza-related pneumonia, New York City

\begin{tabular}{|c|c|c|c|c|c|c|c|c|c|c|c|c|}
\hline & \multicolumn{6}{|c|}{2016 influenza } & \multicolumn{6}{|c|}{2017 influenza } \\
\hline & \multicolumn{3}{|c|}{ October-March } & \multicolumn{3}{|c|}{ July-June } & \multicolumn{3}{|c|}{ October-March } & \multicolumn{3}{|c|}{ July-June } \\
\hline & $\mathrm{aOR}$ & L95\% & U95\% & $\mathrm{aOR}$ & L95\% & U95\% & $\mathrm{aOR}$ & L95\% & U95\% & $\mathrm{aOR}$ & L95\% & U95\% \\
\hline \multicolumn{13}{|l|}{ Age group } \\
\hline $18-39$ & REF & & & REF & & & REF & & & REF & & \\
\hline $40-49$ & 1.05 & 0.84 & 1.32 & 1.03 & 0.84 & 1.27 & 1.49 & 1.27 & 1.74 & 1.47 & 1.26 & 1.71 \\
\hline $50-59$ & 1.55 & 1.29 & 1.87 & 1.51 & 1.27 & 1.79 & 2.25 & 1.97 & 2.57 & 2.20 & 1.94 & 2.51 \\
\hline $60-69$ & 1.46 & 1.17 & 1.82 & 1.47 & 1.20 & 1.80 & 1.98 & 1.70 & 2.31 & 1.96 & 1.69 & 2.27 \\
\hline $70-79$ & 1.91 & 1.51 & 2.40 & 1.98 & 1.60 & 2.46 & 2.62 & 2.22 & 3.08 & 2.59 & 2.21 & 3.03 \\
\hline $80+$ & 3.34 & 2.65 & 4.21 & 3.44 & 2.78 & 4.26 & 4.36 & 3.69 & 5.14 & 4.23 & 3.60 & 4.96 \\
\hline \multicolumn{13}{|l|}{ Sex } \\
\hline Male & $\mathrm{REF}$ & & & REF & & & & & & & & \\
\hline Female & 1.04 & 0.94 & 1.15 & 1.02 & 0.92 & 1.12 & 0.99 & 0.92 & 1.07 & 0.98 & 0.92 & 1.06 \\
\hline \multicolumn{13}{|l|}{ Race/ethnicity } \\
\hline White non-Hispanic & REF & & & REF & & & & & & & & \\
\hline Black non-Hispanic & 1.27 & 1.08 & 1.50 & 1.25 & 1.07 & 1.45 & 1.22 & 1.09 & 1.36 & 1.23 & 1.11 & 1.37 \\
\hline Asian and Pacific Islander & 0.78 & 0.64 & 0.95 & 0.77 & 0.64 & 0.93 & 0.50 & 0.43 & 0.58 & 0.52 & 0.45 & 0.59 \\
\hline Other non-Hispanic & 1.06 & 0.85 & 1.33 & 1.05 & 0.85 & 1.29 & 0.91 & 0.78 & 1.06 & 0.89 & 0.76 & 1.03 \\
\hline Hispanic & 1.60 & 1.38 & 1.86 & 1.60 & 1.39 & 1.83 & 1.20 & 1.09 & 1.33 & 1.20 & 1.09 & 1.33 \\
\hline Unknown & 0.75 & 0.58 & 0.97 & 0.79 & 0.63 & 1.00 & 0.62 & 0.52 & 0.74 & 0.63 & 0.53 & 0.74 \\
\hline \multicolumn{13}{|l|}{ Dual Medicare/Medicaid } \\
\hline No & REF & & & REF & & & & & & & & \\
\hline Yes & 1.47 & 1.25 & 1.72 & 1.48 & 1.27 & 1.71 & 1.39 & 1.25 & 1.55 & 1.40 & 1.27 & 1.55 \\
\hline \multicolumn{13}{|l|}{ Pre-existing conditions } \\
\hline Heart disease & 1.86 & 1.64 & 2.10 & 1.83 & 1.64 & 2.05 & 1.99 & 1.83 & 2.17 & 2.00 & 1.84 & 2.17 \\
\hline Asthma & 2.79 & 2.49 & 3.12 & 2.83 & 2.54 & 3.15 & 2.81 & 2.59 & 3.04 & 2.88 & 2.67 & 3.11 \\
\hline Diabetes & 1.14 & 1.02 & 1.27 & 1.13 & 1.02 & 1.26 & 1.33 & 1.23 & 1.43 & 1.33 & 1.24 & 1.43 \\
\hline Cancer & 1.50 & 1.29 & 1.74 & 1.48 & 1.28 & 1.70 & 1.26 & 1.13 & 1.41 & 1.25 & 1.12 & 1.39 \\
\hline Kidney disease & 2.50 & 2.18 & 2.87 & 2.40 & 2.11 & 2.72 & 2.15 & 1.95 & 2.36 & 2.17 & 1.98 & 2.38 \\
\hline Liver disease & 1.26 & 1.07 & 1.48 & 1.36 & 1.17 & 1.58 & 1.35 & 1.21 & 1.50 & 1.36 & 1.23 & 1.52 \\
\hline Dementia & 1.49 & 1.28 & 1.75 & 1.41 & 1.21 & 1.63 & 1.32 & 1.18 & 1.48 & 1.30 & 1.16 & 1.46 \\
\hline Rheumatoid arthritis & 1.21 & 0.94 & 1.57 & 1.21 & 0.95 & 1.54 & 1.01 & 0.82 & 1.24 & 1.04 & 0.85 & 1.27 \\
\hline
\end{tabular}

All models are adjusted for age, race/ethnicity, sex, dual eligibility, and all pre-existing conditions and run using logistic regression. $A O R$, adjusted odds ratio; $C I$, confidence interval (source: New York State Medicaid Claims, 2015-2020) 
Table 5 Comparing patient demographic and clinical characteristics in hospitalizations with a primary diagnosis of COVID-19 versus any diagnosis of COVID-19, New York City

All models are adjusted for age, race/ethnicity, sex, dual eligibility, and all pre-existing conditions and run using logistic regression. $A O R$, adjusted odds ratio; $C I$, confidence interval (source: New York State Medicaid Claims, 2015-2020)

\begin{tabular}{|c|c|c|c|c|c|c|}
\hline & \multicolumn{6}{|c|}{ COVID-19 } \\
\hline & \multicolumn{3}{|c|}{ Primary diagnosis } & \multicolumn{3}{|c|}{ Any diagnosis } \\
\hline & $\mathrm{aOR}$ & L95\% & U95\% & $\mathrm{aOR}$ & L95\% & U95\% \\
\hline \multicolumn{7}{|l|}{ Age group } \\
\hline $18-39$ & REF & & & REF & & \\
\hline $40-49$ & 2.54 & 2.31 & 2.79 & 1.38 & 1.30 & 1.47 \\
\hline $50-59$ & 3.76 & 3.46 & 4.09 & 1.81 & 1.71 & 1.91 \\
\hline $60-69$ & 4.29 & 3.93 & 4.68 & 1.96 & 1.85 & 2.08 \\
\hline $70-79$ & 5.00 & 4.51 & 5.53 & 2.16 & 2.01 & 2.33 \\
\hline $80+$ & 5.66 & 5.08 & 6.31 & 2.43 & 2.25 & 2.62 \\
\hline \multicolumn{7}{|l|}{ Sex } \\
\hline Male & REF & & & REF & & \\
\hline Female & 0.66 & 0.63 & 0.69 & 0.75 & 0.72 & 0.77 \\
\hline \multicolumn{7}{|l|}{ Race/ethnicity } \\
\hline White non-Hispanic & REF & & & REF & & \\
\hline Black non-Hispanic & 1.01 & 0.95 & 1.08 & 0.99 & 0.94 & 1.04 \\
\hline Asian and Pacific Islander & 0.46 & 0.42 & 0.50 & 0.43 & 0.40 & 0.46 \\
\hline Other non-Hispanic & 0.92 & 0.85 & 1.01 & 0.92 & 0.86 & 0.98 \\
\hline Hispanic & 1.02 & 0.95 & 1.08 & 0.98 & 0.93 & 1.03 \\
\hline Unknown & 0.90 & 0.85 & 0.96 & 0.87 & 0.83 & 0.92 \\
\hline \multicolumn{7}{|l|}{ Dual Medicare/Medicaid } \\
\hline No & REF & & & REF & & \\
\hline Yes & 0.94 & 0.87 & 1.02 & 0.91 & 0.86 & 0.97 \\
\hline \multicolumn{7}{|l|}{ Pre-existing conditions } \\
\hline Heart disease & 1.71 & 1.62 & 1.80 & 1.77 & 1.70 & 1.84 \\
\hline Asthma & 1.44 & 1.36 & 1.52 & 1.32 & 1.26 & 1.38 \\
\hline Diabetes & 1.70 & 1.62 & 1.78 & 1.66 & 1.61 & 1.73 \\
\hline Cancer & 1.06 & 0.99 & 1.14 & 1.12 & 1.06 & 1.18 \\
\hline Kidney disease & 2.27 & 2.14 & 2.41 & 2.36 & 2.26 & 2.47 \\
\hline Liver disease & 1.48 & 1.39 & 1.57 & 1.54 & 1.47 & 1.62 \\
\hline Dementia & 1.73 & 1.61 & 1.86 & 1.99 & 1.88 & 2.10 \\
\hline Rheumatoid arthritis & 1.20 & 1.06 & 1.36 & 1.10 & 0.99 & 1.22 \\
\hline
\end{tabular}


Table 6 Adjusted odds ratios for hospitalizations with Influenza-like-Illness during the 2016 and 2017 influenza seasons, New York City

\begin{abstract}
All models are adjusted for age, race/ethnicity, sex, dual eligibility, and all pre-existing conditions and run using logistic regression. $A O R$, adjusted odds ratio; $C I$, confidence interval (source: New York State Medicaid Claims, 2015-2020)
\end{abstract}

\begin{tabular}{|c|c|c|c|c|c|c|}
\hline & \multicolumn{3}{|c|}{2016 influenza } & \multicolumn{3}{|c|}{2017 influenza } \\
\hline & \multicolumn{3}{|c|}{$N=24,485$} & \multicolumn{3}{|c|}{$N=35,752$} \\
\hline & $\mathrm{aOR}$ & $\mathrm{L} 95 \%$ & U95\% & $\mathrm{aOR}$ & $\mathrm{L} 95 \%$ & U95\% \\
\hline \multicolumn{7}{|l|}{ Age group } \\
\hline $18-39$ & REF & & & REF & & \\
\hline $40-49$ & 1.49 & 1.41 & 1.57 & 1.45 & 1.39 & 1.51 \\
\hline $50-59$ & 1.93 & 1.85 & 2.02 & 2.04 & 1.96 & 2.11 \\
\hline $60-69$ & 1.75 & 1.66 & 1.84 & 1.83 & 1.75 & 1.91 \\
\hline 70-79 & 2.09 & 1.97 & 2.21 & 1.99 & 1.89 & 2.09 \\
\hline $80+$ & 3.09 & 2.92 & 3.28 & 2.93 & 2.78 & 3.08 \\
\hline \multicolumn{7}{|l|}{ Sex } \\
\hline Male & REF & & & REF & & \\
\hline Female & 0.79 & 0.77 & 0.81 & 0.80 & 0.78 & 0.81 \\
\hline \multicolumn{7}{|l|}{ Race/ethnicity } \\
\hline White non-Hispanic & REF & & & REF & & \\
\hline Black non-Hispanic & 1.41 & 1.35 & 1.46 & 1.25 & 1.21 & 1.30 \\
\hline Asian and Pacific Islander & 0.57 & 0.54 & 0.60 & 0.48 & 0.46 & 0.50 \\
\hline Other non-Hispanic & 1.04 & 0.99 & 1.10 & 0.96 & 0.91 & 1.00 \\
\hline Hispanic & 1.22 & 1.18 & 1.27 & 1.09 & 1.06 & 1.13 \\
\hline Unknown & 0.61 & 0.57 & 0.65 & 0.53 & 0.50 & 0.56 \\
\hline \multicolumn{7}{|l|}{ Dual Medicare/Medicaid } \\
\hline No & REF & & & REF & & \\
\hline Yes & 1.34 & 1.29 & 1.39 & 1.13 & 1.09 & 1.16 \\
\hline \multicolumn{7}{|l|}{ Pre-existing conditions } \\
\hline Heart disease & 2.17 & 2.10 & 2.23 & 2.18 & 2.12 & 2.24 \\
\hline Asthma & 2.90 & 2.81 & 2.98 & 2.70 & 2.63 & 2.77 \\
\hline Diabetes & 1.20 & 1.17 & 1.24 & 1.29 & 1.26 & 1.32 \\
\hline Cancer & 1.52 & 1.46 & 1.58 & 1.47 & 1.42 & 1.52 \\
\hline Kidney disease & 2.41 & 2.32 & 2.49 & 2.48 & 2.40 & 2.55 \\
\hline Liver disease & 1.63 & 1.56 & 1.69 & 1.70 & 1.65 & 1.76 \\
\hline Dementia & 1.71 & 1.64 & 1.79 & 1.91 & 1.84 & 1.98 \\
\hline Rheumatoid arthritis & 1.24 & 1.16 & 1.33 & 1.24 & 1.16 & 1.32 \\
\hline
\end{tabular}

Acknowledgements We gratefully acknowledge the funding for this research came from the Russell Sage Foundation. We would also like to thank Steve Schoenbaum for his thoughtful review and comments on this manuscript.

Funding Russell Sage Foundation

\section{Declarations}

Disclaimer The views and opinions expressed in this presentation are those of the author and do not necessarily reflect the official policy or position of the New York State Department of Health. Examples of analysis performed within this article are only examples. They should not be utilized in real-world analytic products.

\section{References}

1. Mein SA. COVID-19 and health disparities: the reality of "the Great Equalizer" [Internet]. Vol. 35, Journal of General Internal Medicine. Springer; 2020 [cited 2021 Jan 19]. p. 2439-40. Available from: https://www.ncbi.nlm. nih.gov/pmc/articles/PMC7224347/

2. Medical Association A. Racial and ethnic health disparities related to COVID-19. JAMA [Internet]. 2021 [cited 2021 Jan 21]; Available from: https://www.kff.org/coron avirus-covid-

3. Thompson CN, Baumgartner J, Pichardo C, Toro B, Li L, Arciuolo R, et al. COVID-19 Outbreak - New York City, February 29-June 1, 2020. MMWR morbidity and mortality weekly report [Internet]. 2020 Nov 20 [cited 2021 
May 16];69(46):1725-9. Available from: https://pubmed. ncbi.nlm.nih.gov/33211680/

4. Zhou Y, Yang Q, Chi J, Dong B, Lv W, Shen L, et al. Comorbidities and the risk of severe or fatal outcomes associated with coronavirus disease 2019: a systematic review and meta-analysis. Vol. 99, International Journal of Infectious Diseases. Elsevier B.V.; 2020. p. 47-56.

5. Yancy CW. COVID-19 and African Americans [Internet]. Vol. 323, JAMA - Journal of the American Medical Association. American Medical Association; 2020 [cited 2021 May 16]. p. 1891-2. Available from: https://www.washi ngtonpost.com/nation/

6. COVID-19 racial and ethnic disparities [Internet]. [cited 2021 May 16]. Available from: https://www.cdc.gov/ coronavirus/2019-ncov/community/health-equity/racialethnic-disparities/index.html

7. Krishnan L, Ogunwole SM, Cooper LA. Historical insights on coronavirus disease 2019 (COVID-19), the 1918 influenza pandemic, and racial disparities: illuminating a path forward. Annals of internal medicine [Internet]. 2020 Sep 15 [cited 2021 May 16];173(6):474-81. Available from: https://www.ncbi.nlm.nih.gov/pmc/articles/ PMC7298913/

8. Flu disparities among racial and ethnic minority groups I CDC [Internet]. [cited 2021 May 16]. Available from: https://www.cdc.gov/flu/highrisk/disparities-racial-ethnicminority-groups.html

9. Blumenshine P, Reingold A, Egerter S, Mockenhaupt R, Braveman P, Marks J. Pandemic influenza planning in the United States from a health disparities perspective [Internet]. Vol. 14, Emerging Infectious Diseases. Centers for Disease Control and Prevention (CDC); 2008 [cited 2021 May 16]. p. 709-15. Available from: https://www.ncbi. nlm.nih.gov/pmc/articles/PMC2600245/

10. Quinn SC, Kumar S, Freimuth VS, Musa D, CastenedaAngarita N, Kidwell K. Racial disparities in exposure, susceptibility, and access to health care in the US H1N1 influenza pandemic. American Journal of Public Health [Internet]. 2011 Feb 1 [cited 2021 Feb 4];101(2):285-93. Available from: https://www.ncbi.nlm.nih.gov/pmc/artic les/PMC3020202/

11. National Center for Health Statistics the. Announcement New ICD 10 code for coronavirus 2202020 [Internet]. 2020 [cited 2020 May 27]. Available from: https://www. cdc.gov/coronavirus/index.html

12. Clinical Classifications Software (CCS) for ICD-10-PCS (beta version) [Internet]. [cited 2021 May 16]. Available from: https://www.hcup-us.ahrq.gov/toolssoftware/ccs10/ $\operatorname{ccs} 10 . j \mathrm{sp}$

13. Williamson EJ, Walker AJ, Bhaskaran $\mathrm{K}$, Bacon $\mathrm{S}$, Bates C, Morton CE, et al. Factors associated with COVID-19-related death using OpenSAFELY. Nature [Internet]. 2020 Aug 20 [cited 2021 May 16];584(7821):430-6. Available from: https://doi.org/10. 1038/s41586-020-2521-4

14. Mackey K, Ayers C, Kondo K, Saha S, Advani S, S Y, et al. Racial and ethnic disparities in COVID-19-related infections, hospitalizations, and deaths : a systematic review. Annals of internal medicine [Internet]. 2021 Mar 1 [cited 2021 Sep 28];174(3):362-73. Available from: https://pubmed.ncbi.nlm.nih.gov/33253040/

15. Brehm TT, van der Meirschen M, Hennigs A, Roedl K, Jarczak D, Wichmann D, et al. Comparison of clinical characteristics and disease outcome of COVID-19 and seasonal influenza. Scientific Reports [Internet]. 2021 Dec 1 [cited 2021 May 20];11(1):5803. Available from https:// doi.org/10.1038/s41598-021-85081-0

16. MW D, A M, GS T, SJ H, RD P, KM B, et al. Comparison between patients hospitalized with influenza and COVID-19 at a tertiary care center. Journal of general internal medicine [Internet]. 2021 Jun 1 [cited 2021 Jul 14];36(6):1689-95. Available from: https://pubmed.ncbi. nlm.nih.gov/33738759/

17. Li P, Wang Y, Peppelenbosch MP, Ma Z, Pan Q. Systematically comparing COVID-19 with the 2009 influenza pandemic for hospitalized patients. International Journal of Infectious Diseases [Internet]. 2021 Jan 1 [cited 2021 Jul 14];102:375. Available from: https://pubmed.ncbi.nlm. nih.gov/33189938/

18. M L, J J, F B, F A, J W. Clinical outcomes and characteristics of patients hospitalized for Influenza or COVID-19 in Germany. International journal of infectious diseases : IJID : official publication of the International Society for Infectious Diseases [Internet]. $2021 \mathrm{Feb} 1$ [cited $2021 \mathrm{Jul}$ 14];103:316-22. Available from: https://pubmed.ncbi. nlm.nih.gov/33279652/

19. Cates J. Risk for in-hospital complications associated with COVID-19 and influenza - Veterans Health Administration, United States, October 1, 2018-May 31, 2020. MMWR Morbidity and Mortality Weekly Report [Internet]. 2020 Oct 23 [cited 2021 Jul 14];69(42):1528-34. Available from: https://www.cdc.gov/mmwr/volumes/69/ $\mathrm{wr} / \mathrm{mm} 6942 \mathrm{e} 3 . \mathrm{htm}$

20. NL C, NA S, KI D, KP S, MR T, CC S, et al. Comparison of clinical features and outcomes in critically ill patients hospitalized with COVID-19 versus influenza. Annals of the American Thoracic Society [Internet]. 2021 Apr 1 [cited 2021 Jul 14];18(4):632-40. Available from: https:// pubmed.ncbi.nlm.nih.gov/33183067/

21. Trick WE, Badri S, Doshi K, Zhang H, Rezai K, Hoffman MJ, et al. Epidemiology of COVID-19 vs. influenza: differential failure of COVID-19 mitigation among Hispanics, Cook County Health, Illinois. PLOS ONE [Internet]. 2021 Jan 1 [cited 2021 Jul 14];16(1):e0240202. Available from: https://journals.plos.org/plosone/article?id=https:// doi.org/10.1371/journal.pone.0240202

22. Romano SD. Trends in racial and ethnic disparities in COVID-19 hospitalizations, by region - United States, March-December 2020. MMWR Morbidity and Mortality Weekly Report [Internet]. 2021 Apr 16 [cited 2021 Jul 14];70(15):560-5. Available from: https://www.cdc.gov/ $\mathrm{mmwr} /$ volumes/70/wr/mm7015e2.htm

23. Kadri SS, Gundrum J, Warner S, Cao Z, Babiker A, Klompas M, et al. Uptake and accuracy of the diagnosis code for Covid-19 among US hospitalizations [Internet]. Vol. 324, JAMA - Journal of the American Medical 
Association. American Medical Association; 2020 [cited 2021 May 16]. p. 2553-4. Available from: https://jaman etwork.com/

24. Summary of the 2017-2018 Influenza Season I CDC [Internet]. [cited 2021 Jul 14]. Available from: https:// www.cdc.gov/flu/about/season/flu-season-2017-2018.htm

25. Summary of the 2016-2017 Influenza Season I CDC [Internet]. [cited 2021 Jul 14]. Available from: https:// www.cdc.gov/flu/about/season/flu-season-2016-2017.htm
26. How CDC Classifies Flu Severity I CDC [Internet]. [cited 2021 May 16]. Available from: https://www.cdc.gov/flu/ about/classifies-flu-severity.htm

Publisher's Note Springer Nature remains neutral with regard to jurisdictional claims in published maps and institutional affiliations. 